\title{
Public Health Orientation Program (PHOP): Persepsi Dokter Internship Fakultas Kedokteran Universitas Padjadjaran
}

\author{
Sharon Gondodiputro, Sekar Ayu Paramita, Indah Amalia, Henni Djuhaeni \\ Departemen Ilmu Kesehatan Masyarakat Fakultas Kedokteran Universitas Padjadjaran Bandung
}

\begin{abstract}
Abstrak
Perubahan paradigma sakit menjadi sehat, kuratif menjadi preventif dan berbasis komunitas menempatkan ilmu kesehatan masyarakat yang dikemas dalam Public Health Oriented Program (PHOP) sebagai materi yang sangat penting di Fakultas Kedokteran Unpad. Persepsi mahasiswa mengenai materi dalam kurikulum pendidikan dapat menggambarkan bagaimana efektivitas kurikulum tersebut. Atas dasar tersebut maka dilakukan penelitian tentang persepsi dokter internship FK Unpad mengenai manfaat PHOP pada saat mereka menjalankan internship. Penelitian deskriptif dilakukan terhadap 97 dokter Fakultas Kedokteran Unpad kelas reguler Angkatan 2007 dan 2008 (respons rate 74,2\%), telah atau sedang melakukan program internship periode Juli-November 2014. Kuesioner yang telah diuji coba dan divalidasi, berisi 52 pertanyaan skala Likert, dikelompokkan menjadi 4 kelompok serta, disebarkan kepada responden menggunakan Research Electronic Data Capture (REDCap). Pengambilan sampel menggunakan consecutive sampling. Data diolah menggunakan distribusi frekuensi dan narasi. Hasil penelitian menunjukkan sebagian besar responden menyatakan bahwa materi-materi yang terdapat di PHOP bermanfaat pada waktu internship, namun beberapa topik kurang aplikatif, peranan mereka sebagai dokter fungsional, tidak diberi kesempatan untuk melakukan fungsi manajemen, preventif, dan promotif di masyarakat. Dari hasil ini dapat disimpulkan, perlu ada penyesuaian materi lebih aplikatif, laboratorium khusus untuk PHOP, mendatangkan expert dari lapangan dan wahana intership melibatkan dokter dalam bidang manajemen, preventif, dan promotif di masyarakat. [MKB. 2015;47(2):115-23]
\end{abstract}

Kata kunci: Internship, persepsi, Public Health Oriented Program (PHOP)

\section{Public Health Orientation Program (PHOP): Perception of Medical Doctor Internship Program Participants at the Faculty of Medicine, Universitas Padjadjaran}

\begin{abstract}
The shift from disease paradigm to healthy paradigm, from curative to preventive and community-based medical education has positioned the Public Health Oriented Program (PHOP) as a very important program of the Faculty of Medicine, Universitas Padjadjaran. Students' perception of the educational curriculum materials can describe the effectiveness of the curriculum. Based on this situation, the aim of this study was to describe the perception of doctors who participated in the internship program of the Faculty of Medicine, Universitas Padjadjaran on the benefits of PHOP. A descriptive study was carried out on 97 doctors of the Faculty of Medicine class 2007 and 2008 (response rate 74.2\%) who had been and was involved in the internship program as participants during July-November 2014. A validated questionnaire was used, containing 52 questions in Likert scale, divided into 4 groups of questions that was distributed to the respondents using Research Electronic Data Capture (REDcap). A consecutive sampling was used. The data was analyzed using frequency distribution and narratives. The results showed that most of the respondents stated that the materials in PHOP were very useful during internship but some topics were less applicable because the main role they played during internship was the role of a clinician and they were not given the opportunity to perform management, preventive and promotive functions in the community. From these results it can be concluded that there are needs for material adjustment towards more applicable, special laboratory activities for PHOP, inviting public health practitioners/experts to give lecture, and creating opportunities for the students to apply management, preventive and promotive actions during internship. [MKB. 2015;47(2):115-23]
\end{abstract}

Key words: Internship, perception, Public Health Oriented Program (PHOP)

Korespondensi: Sharon Gondodiputro, dr., MARS, MH, Departemen Ilmu Kesehatan Masyarakat. Fakultas Kedokteran Universitas Padjadjaran Bandung, Jalan Eijkman No. 38 Bandung, Telepon: 022-2038030, mobile 0811234624, e-mail: sharon gondodiputro@yahoo.com 


\section{Pendahuluan}

Pentingnya pendidikan kedokteran berbasis komunitas di kurikulum sarjana kedokteran telah divalidasi dalam Pendidikan Kedokteran, termasuk di Indonesia. Perubahan paradigma dari kuratif menjadi preventif telah membuat pendidikan kedokteran berbasis komunitas itu menjadi sangat penting. Menurut Navinan dkk. ${ }^{1}$ sebagian kecil lulusan dokter akan memilih Kesehatan Masyarakat atau Komunitas sebagai spesialisasinya, akan tetapi kurikulum sarjana kedokteran yang lengkap mengenai kesehatan masyarakat adalah keadaan yang esensiil untuk seluruh dokter. Ilmu kesehatan masyarakat merupakan kompetensi yang sangat penting bagi seorang dokter, terutama pada layanan primer. $^{2}$ Layanan primer merupakan pertama kali pasien atau masyarakat masuk ke dalam suatu sistem pelayanan kesehatan profesional dan juga memberikan pelayanan kesehatan yang komprehensif, yang tidak hanya mementingkan kuratif, melainkan juga preventif dan promotif., 3,4 Pentingnya ilmu kesehatan masyarakat akibat perubahan pelayanan dari kuratif menjadi preventif disebutkan dalam Standar Kompetensi Dokter Indonesia (SKDI) 2012. Perubahan Sistem Kesehatan Nasional di era Jaminan Kesehatan mengakibatkan institusi pendidikan kedokteran sebagai supply side harus dapat menghasilkan dokter yang dapat memberikan pelayanan sesuai kebutuhan dasar kesehatan masyarakat sebagai peserta BPJS (demand side).

Fakultas Kedokteran Universitas Padjadjaran (FKUP) adalah salah satu institusi pendidikan kedokteran yang menempatkan ilmu kesehatan masyarakat sebagai materi yang paling penting pada program sarjana kedokteran di dalam mempersiapkan lulusannya untuk dapat bekerja di suatu layanan primer. Materi ilmu kesehatan masyarakat di Fakultas Kedokteran Unpad diatur dalam kurikulum Public Health Oriented Program atau PHOP, yang terdiri atas Pengantar Ilmu Kesehatan Masyarakat, Kesehatan Lingkungan dan Kesehatan Kerja, dan Manajemen Pelayanan Kesehatan serta Kedokteran Keluarga.

Persepsi para mahasiswa mengenai suatu materi di dalam kurikulum pendidikan, dapat menggambarkan bagaimana efektivitas dari suatu kurikulum tersebut. Persepsi yang buruk terhadap kurikulum salah satunya adalah karena implementasi kurikulum yang kurang baik, ${ }^{6}$ sementara persepsi mahasiswa yang baik akan meningkatkan motivasi mereka untuk belajar. ${ }^{1}$ Penilaian persepsi mahasiswa mengenai suatu kurikulum jika dilakukan secara rutin, diakui sangat berguna dalam rangka pembentukan kurikulum agar lebih bermanfaat dan dapat diterima dengan baik oleh mahasiswa. Atas dasar tersebut maka dilakukan penelitian tentang persepsi dokter internship mengenai manfaat topik-topik Kurikulum PHOP di Program Sarjana Kedokteran pada saat mereka sudah atau sedang menjalankan internship di puskesmas maupun rumah sakit.

\section{Metode}

Penelitian ini merupakan penelitian deskriptif dengan subjek penelitian adalah dokter internship Fakultas Kedokteran Unpad dengan kriteria inklusi yaitu mahasiswa kedokteran kelas reguler Angkatan 2007 dan 2008, telah atau sedang melakukan program internship di puskesmas dan bersedia menjadi responden. Penelitian ini dilakukan selama bulan Juli-November 2014. Kriteria eksklusi adalah mahasiswa kedokteran kelas reguler Angkatan 2007 dan 2008 yang sedang atau telah menjalani program internship di puskesmas, namun tidak dapat dihubungi. Pengambilan sampel menggunakan consecutive sampling. Consecutive sampling merupakan jenis non-probability terbaik dan juga sering kali merupakan cara yang paling mudah. Dari 97 sampel yang dibutuhkan, terdapat 72 responden yang sudah mengembalikan kuesioner (respons rate $=74,2 \%$ ). Pengumpulan data menggunakan kuesioner yang dikelompokkan menjadi 4 kelompok pertanyaan dengan skala Likert 4 poin, dimulai dari "sangat bermanfaat" hingga "tidak bermanfaat". Jumlah pertanyaan adalah 52 buah, terdiri atas pertanyaan-pertanyaan mengenai pentingnya topik-topik di Ilmu Kesehatan Masyarakatantara lain Pengantar Ilmu Kesehatan Masyarakat sebanyak 11 pertanyaan, Kesehatan Lingkungan dan Kesehatan Kerja sebanyak 15 pertanyaan, Manajemen Pelayanan Kesehatan sebanyak 10 pertanyaan, serta Kedokteran Keluarga sebanyak 16 pertanyaan. Pada jawaban pertanyaan "kurang bermanfaat" dan juga "tidak bermanfaat", responden mampu menuliskan alasan mengapa topik-topik tersebut kurang atau tidak bermanfaat secara naratif disertai dengan usulan perbaikan kurikulum. Kuesioner telah diujicoba pada 22 responden yang terdiri atas 14 orang mahasiswa kedokteran angkatan 2007 dan 8 orang mahasiswa Angkatan 2008. Uji realibilitas menggunakan Chronbach's Alpha dan uji validitas menggunakan Kaiser-MeiyerOikin. Kuesioner yang telah direvisi disebarkan kepada responden mempergunakan Research 
Electronic Data Capture (REDCap) yaitu suatu aplikasi yang berbasis website untuk melakukan survey online. Persetujuan etik telah diberikan oleh Komite Etik Penelitian Kesehatan Nomor 487a/UN6.C2.1.2/KEPK/PN/2014. Data diolah menggunakan distribusi frekuensi dan narasi.

\section{Hasil}

Saat ini intership merupakan suatu tahapan awal dokter yang baru lulus pendidikan kedokteran menghadapi masyarakat dan menjadi bagian sistem kesehatan. Hasil dari persepsi mahasiswa mengenai manfaat dari materi Pengantar Ilmu Kesehatan Masyarakat diperlihatkan pada Tabel 1.

Pada Tabel 1 tampak bahwa hampir seluruh responden menyatakan terdapat manfaat akan topik pada materi Ilmu Kesehatan Masyarakat, terutama tentang Perilaku hidup bersih dan sehat, Prinsip dasar Pelayanan Kesehatan Dasar, konsep pembangunan kesehatan masyarakat masyarakat desa, dan konsep dasar Puskesmas, Etika kesehatan masyarakat, Pencegahan HIV/ AIDS, Gizi Masyarakat serta Tobacco control, namun demikian masih terdapat 2 topik yang dirasakan oleh responden kurang bermanfaat yaitu Filosofi Ilmu Kesehatan Masyarakat dan Manajemen Bencana. Tanggapan responden adalah "materi filosofi kurang praktis untuk diterapkan". Selanjutnya, terdapat berbagai tanggapan tentang manajemen bencana, yaitu "Daerah internship saya bukan daerah rawan bencana dan tidak ada kejadian wabah dan bencana saat internship".

Beberapa responden menyatakan bahwa mereka ingin sekali menerapkan materi ilmu kesehatan masyarakat pada waktu internship, namun terdapat beberapa kendala yaitu selama internship lebih bertindak sebagai seorang dokter fungsional, kurangnya waktu ke lapangan atau masyarakat, materi belum dapat diintegrasikan dalam kehidupan klinisi, dan hanya melanjutkan program yang sudah berjalan di puskesmas. Khusus pada poin pencegahan terhadap HIV/ AIDS, salah satu responden yang menyatakan "saya memerlukan contoh langsung mengenai penerapan materi HIV/AIDS ketika berhadapan dengan masyarakat. Cara masuk ke dalam komunitas ODHA dan bagaimana mengedukasi keluarga dan masyarakat yang tinggal di sekitar

Tabel 1 Persepsi Responden mengenai Manfaat Materi Pengantar Ilmu Kesehatan Masyarakat

\begin{tabular}{lcccc}
\hline \multicolumn{1}{c}{ Pertanyaan } & $\begin{array}{c}\text { Sangat } \\
\text { Bermanfaat } \\
\mathbf{( \% )}\end{array}$ & $\begin{array}{c}\text { Bermanfaat } \\
\mathbf{( \% )}\end{array}$ & $\begin{array}{c}\text { Kurang } \\
\text { Bermanfaat } \\
\mathbf{( \% )}\end{array}$ & $\begin{array}{c}\text { Tidak } \\
\text { Bermanfaat } \\
\text { (\%) }\end{array}$ \\
\hline $\begin{array}{l}\text { Filosofi dasar, definisi, tujuan, strategi, dan } \\
\text { sejarah Ilmu Kesehatan Masyarakat (di } \\
\text { dunia dan Indonesia) }\end{array}$ & 2,8 & 76,4 & 20,8 & 0 \\
$\begin{array}{l}\text { Sistem Kesehatan Nasional } \\
\text { Etika Kesehatan Masyarakat }\end{array}$ & 13,9 & 73,6 & 12,5 & 0 \\
Hukum-hukum kesehatan masyarakat & 26,4 & 68,1 & 5,6 & 0 \\
$\begin{array}{l}\text { Prinsip dasar Pelayanan Kesehatan } \\
\text { Dasar, konsep Pembangunan Kesehatan }\end{array}$ & 11,1 & 70,8 & 15,3 & 2,8 \\
Masyarakat masyarakat Desa, dan konsep & 30,6 & 58,3 & 11,1 & 0 \\
Dasar Puskesmas & & & & \\
Pemberdayaan Masyarakat & 19,4 & 69,4 & 9,7 & 1,4 \\
Perilaku Hidup Bersih dan Sehat & 48,6 & 48,6 & 2,8 & 0 \\
Tobacco Control & 20,8 & 56,9 & 19,4 & 2,8 \\
Gizi Masyarakat & 20,8 & 66,7 & 9,7 & 2,8 \\
Pencegahan HIV/AIDS & 26,4 & 59,7 & 12,5 & 1,4 \\
Manajemen Bencana di Masyarakat & 5,6 & 59,7 & 27,8 & 6,9 \\
\hline
\end{tabular}


Tabel 2 Persepsi Responden Mengenai Manfaat Materi Kesehatan Lingkungan dan Kesehatan Kerja

\begin{tabular}{|c|c|c|c|c|}
\hline Pertanyaan & $\begin{array}{c}\text { Sangat } \\
\text { Bermanfaat }\end{array}$ & Bermanfaat & $\begin{array}{c}\text { Kurang } \\
\text { Bermanfaat }\end{array}$ & $\begin{array}{c}\text { Tidak } \\
\text { Bermanfaat }\end{array}$ \\
\hline $\begin{array}{l}\text { Polusi air, udara, suara, dan polusi di } \\
\text { tempat kerja }\end{array}$ & 18,1 & 68,1 & 13,9 & 0 \\
\hline Saluran pembuangan air limbah (SPAL) & 12,5 & 63,9 & 23,6 & 0 \\
\hline Air bersih & 26,4 & 68,1 & 5,6 & 0 \\
\hline $\begin{array}{l}\text { Pengelolaan makanan yang sehat dan } \\
\text { aman }\end{array}$ & 31,9 & 59,7 & 8,3 & 0 \\
\hline $\begin{array}{l}\text { Makanan sebagai penularan penyakit } \\
\text { (food-borne disease) }\end{array}$ & 33,3 & 61,1 & 5,6 & 0 \\
\hline $\begin{array}{l}\text { Makanan yang menimbulkan } \\
\text { keracunan (food poisoning) }\end{array}$ & 22,2 & 68,1 & 9,7 & 0 \\
\hline Persyaratan rumah sehat & 29,2 & 61,1 & 9,7 & 0 \\
\hline Persyaratan jamban sehat & 18,1 & 63,9 & 18,1 & 0 \\
\hline Pengolahan sampah rumah tangga & 19,4 & 59,7 & 20,8 & 0 \\
\hline Infeksi nosokomial & 31,9 & 62,5 & 5,6 & 0 \\
\hline Pengelolaan limbah rumah sakit & 15,3 & 63,9 & 20,8 & 0 \\
\hline $\begin{array}{l}\text { Perubahan iklim dan pemanasan } \\
\text { global }\end{array}$ & 12,5 & 54,2 & 33,3 & 0 \\
\hline $\begin{array}{l}\text { Hubungan antara pekerjaan pasien dan } \\
\text { timbulnya penyakit }\end{array}$ & 30,6 & 58,3 & 11,1 & 0 \\
\hline Kecelakaan kerja & 30,6 & 61,1 & 8,3 & 0 \\
\hline $\begin{array}{l}\text { Regulasi dan kontrol kesehatan dan } \\
\text { keselamatan kerja }\end{array}$ & 22,2 & 63,9 & 13,9 & 0 \\
\hline
\end{tabular}

ODHA".

Materi kedua di kurikulum Ilmu Kesehatan Masyarakat yaitu Kesehatan Lingkungan dan Kesehatan Kerja. Tabel 2 dapat menggambarkan bagaimana persepsi para mahasiswa terhadap manfaat dari materi Kesehatan Lingkungan dan Kesehatan Kerja.

Seluruh responden setuju bahwa materi kesehatan lingkungan dan juga kesehatan kerja bermanfaat saat melakukan internship. Beberapa topik yang sangat bermanfaat yaitu Air bersih, Pengelolaan Makanan yang sehat dan aman, Makanan sebagai penularan penyakit (food-borne disease), Makanan yang menimbulkan keracunan (food poisoning), Infeksi nosokomial, Hubungan antara pekerjaan pasien dan timbulnya penyakit, Kecelakaan kerja serta regulasi dan kontrol kesehatan dan keselamatan kerja. Terdapat 4 materi yang dirasakan kurang bermanfaat yaitu perubahan iklim dan pemanasan global, saluran pembuangan air limbah (SPAL), pengelolaan sampah rumah tangga, serta pengelolaan limbah rumah sakit.

Topik perubahan iklim dan pemanasan global dirasakan tidak jelas dan tidak ada hubungannya dengan penyakit menular. Tanggapan tentang topik SPAL adalah "Saya tidak berhubungan dengan SPAL waktu saya internship". Khusus materi tentang pengelolaan limbah rumah sakit dirasakan kurang bermanfaat karena responden lebih banyak melakukan pelayanan kesehatan dibanding dengan mengurus manajemen rumah sakit. Tanggapan responden yang cukup menarik adalah tentang kesehatan kerja. Responden merasakan bahwa diperlukan pemberian materi tentang hiperkes dan penyakit-penyakit yang 
Tabel 3 Persepsi Responden Mengenai Manfaat Materi Manajemen Pelayanan Kesehatan

\begin{tabular}{|c|c|c|c|c|}
\hline Pertanyaan & $\begin{array}{c}\text { Sangat } \\
\text { Bermanfaat } \\
(\%) \\
\end{array}$ & $\begin{array}{c}\text { Bermanfaat } \\
(\%)\end{array}$ & $\begin{array}{c}\text { Kurang } \\
\text { Bermanfaat } \\
(\%) \\
\end{array}$ & $\begin{array}{c}\text { Tidak } \\
\text { Bermanfaat } \\
(\%) \\
\end{array}$ \\
\hline Aspek ekonomi dalam sektor kesehatan & 16,7 & 73,6 & 8,3 & 1,4 \\
\hline $\begin{array}{l}\text { Fungsi manajemen (planning- } \\
\text { organizing-actuating-controlling- } \\
\text { evaluating) }\end{array}$ & 23,6 & 68,1 & 8,3 & 0 \\
\hline Penentuan prioritas program & 34,7 & 61,1 & 4,2 & 0 \\
\hline $\begin{array}{l}\text { Sumber daya manusia dalam sektor } \\
\text { kesehatan }\end{array}$ & 20,8 & 65,3 & 13,9 & 0 \\
\hline Pembiayaan kesehatan & 11,1 & 75 & 12,5 & 1,4 \\
\hline Logistik kesehatan & 11,1 & 69,4 & 19,4 & 0 \\
\hline Sistem informasi kesehatan & 16,7 & 70,8 & 12,5 & 0 \\
\hline Kualitas pelayanan kesehatan & 27,8 & 65,3 & 6,9 & 0 \\
\hline Administrasi rumah sakit & 13,9 & 58,3 & 26,4 & 1,4 \\
\hline $\begin{array}{l}\text { Isu pelayanan kesehatan terkini } \\
\text { (seperti desentralisasi, MDGs, Jaminan } \\
\text { Kesehatan Nasional (JKN) / Badan } \\
\text { Penyelenggara Jaminan Sosial (BPJS) }\end{array}$ & 41,7 & 48,6 & 6,9 & 2,8 \\
\hline
\end{tabular}

ditimbulkan oleh limbah atau zat di pabrik. Hasil penelitian tentang persepsi responden terhadap materi Manajemen Pelayanan Kesehatan tampak pada Tabel 3 .

Sebagian besar responden setuju bahwa materi mengenai suatu Manajemen Pelayanan Kesehatan sangat bermanfaat pada saat mereka internship, terutama pada materi mengenai isu pelayanan kesehatan terkini, penentuan prioritas program, fungsi manajemen, serta sumber daya manusia. Terdapat satu materi yang dirasakan kurang bermanfaat yaitu materi administrasi rumah sakit. Sebagian besar responden tersebut menyatakan bahwa selama internship di rumah sakit tidak diberi kesempatan untuk dilibatkan dalam proses manajemen dan administrasi baik di puskesmas maupun di rumah sakit.

Persepsi responden mengenai manfaat dari materi Kedokteran Keluarga pada saat mereka internship tampak pada Tabel 4. Seperti materi lainnya, pada tabel 4 tampak bahwa sebagian besar responden setuju bahwa materi tersebut bermanfaat bagi mereka pada saat internship. Dari 16 pertanyaan, terdapat 11 pertanyaan yang dijawab sangat bermanfaat. Terdapat 3 pertanyaan yang dijawab kurang bermanfaat yaitu tentang persiapan mendirikan tempat praktik, entrepreneur dalam membangun jiwa kewirausahaan, serta entrepreneur di dalam mengenali dan juga memasarkan potensi diri. Tanggapan responden tentang materi-materi tersebut adalah pada saat internship, mereka belum memikirkan untuk mendirikan praktik mandiri dan merasa belum waktunya untuk menjadi entrepreneur.

Tanggapan responden lain yang menarik adalah tentang penggunaan assessment tools seperti genogram, Social, Cultural, Religious, Economic, Education and Medical (SCREEM), dan Adaptation, Partnership, Growth, Affection and Resolve (APGAR). Responden telah mencoba untuk mempergunakan tools tersebut, namun dihadapkan kendala banyaknya pasien di rawat jalan sehingga tidak ada waktu. Bagi pasien di rawat inap, aplikasi penggunaan tools ini lebih mudah dilakukan karena banyak waktu dan dapat menentukan terapi yang diberikan secara holistik.

Pada penelitian ini dilakukan pula suatu identifikasi usulan perbaikan kurikulum dari responden seperti tampak pada Tabel 5. Usulan perbaikan kurikulum lebih menekankan kepada perlunya materi disampaikan secara aplikatif dan menggunakan contoh di lapangan serta modifikasi metode pembelajaran. Usulan banyak diajukan oleh responden adalah pada materi 
Tabel 4 Persepsi Responden mengenai Manfaat Materi Kedokteran Keluarga

\begin{tabular}{|c|c|c|c|c|}
\hline Pertanyaan & $\begin{array}{c}\text { Sangat } \\
\text { Bermanfaat } \\
(\%) \\
\end{array}$ & $\begin{array}{c}\text { Bermanfaat } \\
(\%)\end{array}$ & $\begin{array}{c}\text { Kurang } \\
\text { Bermanfaat } \\
(\%) \\
\end{array}$ & $\begin{array}{c}\text { Tidak } \\
\text { Bermanfaat } \\
(\%) \\
\end{array}$ \\
\hline Prinsip kedokteran keluarga & 31,9 & 61,1 & 6,9 & 0 \\
\hline $\begin{array}{l}\text { Dampak terhadap keluarga yang } \\
\text { diakibatkan oleh anggota keluarga yang } \\
\text { sakit }\end{array}$ & 37,5 & 59,7 & 2,8 & 0 \\
\hline $\begin{array}{l}\text { Dampak terhadap keluarga yang } \\
\text { diakibatkan oleh anggota keluarga yang } \\
\text { hipertensi }\end{array}$ & 43,1 & 55,6 & 1,4 & 0 \\
\hline Pembuatan genogram & 22,2 & 65,3 & 9,7 & 2,8 \\
\hline $\begin{array}{l}\text { Penilaian SCREEM (Social, Cultural, } \\
\text { Religious, Economic, Education and Medical) }\end{array}$ & 11,1 & 73,6 & 13,9 & 1,4 \\
\hline $\begin{array}{l}\text { Penilaian APGAR (Adaptation, Partnership, } \\
\text { Growth, Affection and Resolve) pada fungsi } \\
\text { keluarga }\end{array}$ & 16,7 & 66,7 & 15,3 & 1,4 \\
\hline $\begin{array}{l}\text { Pengelolaan pasien dengan pendekatan } \\
\text { holistik }\end{array}$ & 38,9 & 55,6 & 5,6 & 0 \\
\hline Skrining pada setiap golongan usia & 22,2 & 72,2 & 5,6 & 0 \\
\hline $\begin{array}{l}\text { Imunisasi yang akan diberikan pada setiap } \\
\text { golongan usia }\end{array}$ & 36,1 & 59,7 & 4,2 & 0 \\
\hline Konseling & 27,8 & 66,7 & 5,6 & 0 \\
\hline $\begin{array}{l}\text { Pemeriksaan komprehensif (fisik, mental, } \\
\text { sosial) pada elderly }\end{array}$ & 30,6 & 63,9 & 5,6 & 0 \\
\hline Care giver pada elderly & 20,8 & 70,8 & 6,9 & 1,4 \\
\hline Palliative care & 23,6 & 63,9 & 12,5 & 0 \\
\hline Persiapan mendirikan tempat praktik & 15,3 & 59,7 & 20,8 & 4,2 \\
\hline $\begin{array}{l}\text { Entrepreneur dalam membangun jiwa } \\
\text { kewirausahaan }\end{array}$ & 13,9 & 56,9 & 22,2 & 6,9 \\
\hline $\begin{array}{l}\text { Entrepreneur dalam mengenali dan } \\
\text { memasarkan potensi diri }\end{array}$ & 13,9 & 58,3 & 22,2 & 5,6 \\
\hline
\end{tabular}

Ilmu Kesehatan Masyarakat dibanding dengan materi yang lainnya, seperti harus lebih aplikatif dan banyak contoh dari lapangan. Beberapa topik perlu diperdalam diantaranya isu budaya dan juga masalah kesehatan masyarakat terkini seperti kawasan tanpa rokok, gizi masyarakat, pemberdayaan masyarakat, BPJS dan JKN, serta sistem kesehatan. Dari segi metode pembelajaran didapatkan usulan yang beragam mulai dari disediakan modul-modul, kunjungan lapangan, mendatangkan dosen tamu, dan sebagainya. Usulan yang menarik adalah perlu disiapkan laboratorium khusus yang mengasah keterampilan dan juga pengetahuan di bidang ilmu kesehatan masyarakat, serta kesehatan lingkungan dan kesehatan kerja. Terdapat usulan untuk internship seperti yang dikemukakan oleh responden: "Sebaiknya saat internship di puskesmas, dokter muda diletakkan di manajemen puskesmas, bukan di pelayanan".

\section{Pembahasan}

Keberhasilan peningkatan status kesehatan masyarakat dibuktikan dengan meningkatnya Angka Harapan Hidup (AHH). ${ }^{7}$ Dalam 10 tahun, $\mathrm{AHH}$ Indonesia diproyeksikan meningkat dari 
Tabel 5 Usulan Perbaikan Kurikulum PHOP dari Segi Materi dan Metode Pembelajaran

\begin{tabular}{|c|c|c|c|c|}
\hline $\begin{array}{c}\text { Usulan } \\
\text { Perbaikan } \\
\text { Kurikulum }\end{array}$ & $\begin{array}{l}\text { Ilmu Kesehatan } \\
\text { Masyarakat }\end{array}$ & $\begin{array}{c}\text { Kesehatan } \\
\text { Lingkungan dan } \\
\text { Kesehatan Kerja }\end{array}$ & $\begin{array}{l}\text { Manajemen } \\
\text { Pelayanan } \\
\text { Kesehatan }\end{array}$ & $\begin{array}{l}\text { Kedokteran } \\
\text { Keluarga }\end{array}$ \\
\hline $\begin{array}{l}\text { Materi: Usulan } \\
\text { Umum }\end{array}$ & $\begin{array}{l}\text { - Lebih aplikatif } \\
\text { dengan contoh- } \\
\text { contoh kasus } \\
\text { - Sesuai keadaan } \\
\text { di masyarakat/di } \\
\text { lapangan }\end{array}$ & $\begin{array}{l}\text { - Lebih aplikatif } \\
\text { dengan contoh- } \\
\text { contoh kasus di } \\
\text { lapangan. } \\
\text { - Dilakukan } \\
\text { pengulangan di } \\
\text { tingkat PSPD }\end{array}$ & $\begin{array}{l}\text { - Lebih aplikatif } \\
\text { Materi mengenai } \\
\text { program kesehatan } \\
\text { baru (BPJS, JKN, dll) } \\
\text { diulang kembali pada } \\
\text { saat PSPD dan pra } \\
\text { internship }\end{array}$ & $\begin{array}{l}\text { - Tips dan tricks } \\
\text { melaksanakan } \\
\text { assesment tools } \\
\text { pada pasien } \\
\text { yang banyak } \\
\text { - Contoh praktis }\end{array}$ \\
\hline $\begin{array}{l}\text { Materi: Usulan } \\
\text { khusus }\end{array}$ & $\begin{array}{l}\text { - Pembahasan tentang } \\
\text { budaya } \\
\text { - Pembahasan } \\
\text { isu terkini seperti } \\
\text { kawasan tanpa rokok } \\
\text { dll. } \\
\text { - Gizi masyarakat, } \\
\text { pemberdayaan } \\
\text { masyarakat, BPJS dan } \\
\text { JKN lebih diperdalam } \\
\text { - Sistem kesehatan di } \\
\text { update }\end{array}$ & $\begin{array}{l}\text { - Kecelakaan kerja, } \\
\text { kesehatan kerja, } \\
\text { regulasi serta } \\
\text { kontrol } \\
\text { keselamatan } \\
\text { kerja, hiperkes } \\
\text { diperdalam }\end{array}$ & $\begin{array}{l}\text { - BPJS, JKN diperdalam } \\
\text { - Materi tentang } \\
\text { program kesehatan } \\
\text { diperbanyak }\end{array}$ & $\begin{array}{l}\text { - Palliative Care } \\
\text { diperbanyak } \\
\text { - Etika dokter } \\
\text { dalam hal } \\
\text { enterpreneurship } \\
\text { - Entrepreneurship } \\
\text { dan pendirian } \\
\text { klinik dibuat } \\
\text { lebih mendalam, } \\
\text { lebih menarik, } \\
\text { dan praktis }\end{array}$ \\
\hline $\begin{array}{l}\text { Metode } \\
\text { Pembelajaran }\end{array}$ & $\begin{array}{l}\text { - Disediakan modul } \\
\text { dan jadwal } \\
\text { perkuliahan yang jelas } \\
\text { - Interaksi dengan } \\
\text { masyarakat seperti } \\
\text { fieldtrip ke posyandu, } \\
\text { posbindu, dan } \\
\text { puskesmas } \\
\text { - Diskusi dan studi } \\
\text { interaktif } \\
\text { - Jam kuliah } \\
\text { diperpanjang } \\
\text { - Mendatangkan dosen } \\
\text { tamu profesional/ } \\
\text { lapangan } \\
\text { - Laboratorium: studi } \\
\text { kasus }\end{array}$ & $\begin{array}{l}\text { - Ada praktikum K3 } \\
\text { - Kunjungan } \\
\text { langsung ke } \\
\text { lapangan atau } \\
\text { contoh kasus }\end{array}$ & - Kunjungan lapangan & - Sudah baik \\
\hline
\end{tabular}

70,9 tahun pada tahun 2015-2020 menjadi 72 tahun pada tahun 2025-2030.8 Kesuksesan upaya kesehatan masyarakat di abad ke 20 dapat meningkatkan kualitas hidup; penurunan angka kematian ibu dan bayi, serta eradikasi atau penurunan penyakit menular. Beberapa pencapaian terbesar pada tahun 2001-2010 adalah vaksinasi, pencegahan dan pengendalian penyakit menular, Tobacco control, kesehatan ibu dan anak, keselamatan berkendara, pencegahan penyakit kardiovaskular, keselamatan kerja, dan pencegahan penyakit kanker. ${ }^{9}$ Keadaan ini menunjukkan bahwa ilmu kesehatan masyarakat telah memberikan kontribusi bagi peningkatan status kesehatan masyarakat.
Ilmu kesehatan masyarakat juga terbukti bermanfaat dalam praktik klinis dokter, seperti memahami penyebab dan distribusi penyakit, serta mengidentifikasi pengaruh lingkungan, perilaku, nutrisi, dan lingkungan sosial budaya terhadap timbulnya suatu penyakit. ${ }^{10}$ Memiliki pemahaman akan determinan tentang kesehatan yang dapat memengaruhi kesehatan individu, mengetahui bagaimana berkolaborasi dan juga institusi kesehatan masyarakat, ${ }^{11}$ serta dapat menggunakan sumber daya yang disediakan oleh program kesehatan masyarakat untuk pasien individual, merupakan beberapa luaran penting pendidikan kedokteran. ${ }^{7}$ Studi yang dilakukan Carney dkk. ${ }^{12}$ dan Maeshiro dkk., ${ }^{13}$ menunjukkan 
bahwa diperlukan pengembangan kurikulum pendidikan dokter berdasarkan kemitraan antara institusi pendidikan dan masyarakat sehingga dokter yang dihasilkanpun dapat membantu masyarakat di dalam memecahkan masalah kesehatannya. Kemitraan ini telah dilakukan oleh Fakultas Kedokteran Unpad dengan diadakannya Semiloka penyusunan kurikulum Public Health Oriented Program (PHOP) pada tahun 2007 dengan mengundang berbagai stakeholders dan hasil semiloka ini pertama kali diterapkan pada mahasiswa Angkatan 2007.

Hasil penelitian ini memperlihatkan bahwa sebagian besar responden menyatakan bahwa materi-materi yang terdapat di Kurikulum PHOP bermanfaatbagi mereka saat menjalani internship di masyarakat, baik di puskesmas maupun di rumah sakit. Beberapa responden menyatakan bahwa materi yang didapatkan di PHOP sangat bermanfaat saat di lapangan, namun saat mereka mahasiswa, mereka belum mengerti manfaat tersebut sehingga PHOP kurang diperhatikan apabila dibanding dengan materi kedokteran klinis. Kurangnya pemahaman mahasiswa akan pentingnya suatu subjek, dalam hal ini adalah ilmu kesehatan masyarakat, akan menurunkan minat mahasiswa terhadap materi tersebut. Hal ini seperti ditunjukkan pada hasil penelitian pada mahasiswa kedokteran di Canada, yang memperlihatkan bahwa para mahasiswa sarjana merasa tidak puas dengan kurikulum Public Health dalam pendidikan kedokteran mereka karena tidak memiliki penjelasan yang adekuat akan manfaat ilmu kesehatan masyarakat bagi seluruh dokter, apapun bidang yang diambil. ${ }^{6}$ Berdasarkan penjelasan tersebut maka amat penting bagi para pelaksana kurikulum untuk memberikan overview dan perkenalan mengenai materi sebelum proses belajar mengajar dimulai. Pembagian learning objectives dan juga jadwal pengajaran serta tugas di awal pengajaran dapat menjadi langkah awal pengenalan kurikulum.

Sebagian besar alasan lain responden yang menyatakan kurang/tidak merasakan manfaat topik-topik di dalam kurikulum PHOP adalah karena saat internship, peranan mereka sebagian besar adalah sebagai dokter operasional yang memberikan pelayanan kesehatan terhadap pasien individual. Responden belum mampu mengintegrasikan pengetahuan ilmu kesehatan masyarakat ke dalam praktik kedokteran seperti dapat mengidentifikasi risiko terjadinya penyakit pada pasien tersebut serta melakukan tindakan pencegahan dan promosi kesehatan. ${ }^{15}$

Walaupun PHOP dapat diterapkan pada saat menangani pasien individu, namun tidak dapat dipungkiri bahwa beberapa materi hanya dapat diterapkan jika mereka ikut serta dalam fungsi manajemen, terutama pada topik Manajemen Pelayanan Kesehatan.

Masukan dari responden untuk perbaikan kurikulum yaitu metode pengajaran agar lebih menarik, aplikatif, memperbanyak studi kasus/ hands on secara langsung terhadap masalah yang sesuai dengan apa yang terjadi di masyarakat. Hal ini sejalan dengan penelitian di Sri Langka, yaitu dengan membuat proses belajar yang aktif, menyenangkan, serta memberikan keuntungan personal (karena mahasiswa harus mengetahui pentingnya materi tersebut) akan memotivasi mahasiswa untuk lebih terlibat aktif di dalam pendidikan yang mereka dapat. Sebagai contoh, kegiatan berbasis lapangan seperti communitybased atau family-based yang bersifat studentoriented akan lebih menyenangkan dan juga membuat mereka lebih terlibat. ${ }^{1}$ Penelitian lain oleh Fiebach dkk. ${ }^{15}$ menunjukkan hal yang sama yaitu diperlukan penyusunan kurikulum ilmu kesehatan masyarakat dan sistem kesehatan yang dapat sesuai dengan kebutuhan praktik kedokteran.

Kurikulum berbasis Problem-based Learning (PBL) yang dipadukan dengan pembelajaran langsung dengan masalah-masalah yang ada di masyarakat atau Community-Engaged Learning, diharapkan akan dapat memberikan pengalaman langsung pada mahasiswa kedokteran dengan kasus-kasus di masyarakat. ${ }^{17}$ Penelitian ini tidak lepas dari keterbatasan yaitu kuesioner tidak mencantumkan topik-topik tentang epidemiologi penyakit. Keadaan ini disebabkan karena dalam struktur pendidikan kedokteran di FK Unpad, topik-topik tersebut dikelola oleh Departemen Epidemiologi dan dikemas dalam program yang dinamakan Community Research Program.

Dari penelitian ini dapat disimpulkan bahwa secara keseluruhan materi yang terdapat pada PHOP terintegrasi tahun 2007 masih bermanfaat pada waktu mahasiswa melakukan internship, akan tetapi perlu dilakukan berbagai perubahan suatu metode pembelajaran seperti laboratorium khusus untuk PHOP, yang lebih memberikan contoh-contoh sesuai dengan keadaan lapangan, mendatangkan pakar dari lapangan dan juga pada waktu internship terutama di Puskesmas lebih dilibatkan dalam manajemen puskesmas dan preventif, serta promotif di lapangan. Wahana intership sebaiknya dapat melibatkan peserta internship di dalam bidang tersebut mengingat ilmu manajemen dan administrasi di sarana pelayanan kesehatan merupakan bagian dari kerangka kompetensi dokter di seluruh 
dunia ${ }^{16}$ dan SKDI.

Tim peneliti mengucapkan terima kasih kepada Pimpinan Fakultas Kedokteran Unpad atas dukungan pembiayaan sehingga penelitian ini dapat berjalan.

\section{Daftar Pustaka}

1. Navinan MR, Wijayaratne DR, Rajapakse S. Final-year medical students' perceptions regarding the curriculum in public health. Indian J Community Med. 2011;36(4):26874.

2. Dysinger WS, Pappas JM. A fourth-year medical school rotation in quality, patient safety, and population medicine. Am J Prev Med. 2011;41(4 suppl 3):S200-5.

3. Starfield B. Primary care and equity in health: the importance to effectiveness and equity of responsiveness to people's needs. Humanity Society. 2009;33(1):56-73.

4. Muldoon LK, Hogg WE, Levitt M. Primary care (PC) and primary health care what is the difference?. Can J Public Health. 2006; 97(5):409-11.

5. Tyler IV, Hau M, Buxton JA, Elliott LJ, Harvey BJ, Hockin JC, dkk. Canadian medical students' perceptions of public health education in the undergraduate medical curriculum. Acad Med. 2009;84(9):1307-12.

6. Bunker J, Frazier HS, Mosteller F. Improving health: measuring effects of medical care. Milbank Q. 1994;72:225-58.

7. Bappenas, BPS dan UNFPA. Proyeksi penduduk Indonesia 2010-2035. Jakarta: BPS; 2013.

8. Centers for Disease Control and Prevention (CDC), Ten Great Public Health Achievements in the $20^{\text {th }}$ Century [diunduh Agustus 2014]. Tersedia dari: http://www.cdc.gov/about/ history/tengpha.htm.

9. Fineberg HV. Public health and medicine: where the twain shall meet. Am J Prev Med. 2011;41(4 Suppl 3):S141-S3.

10. McNeal MS, Blumenthal DS. Innovative ways of integrating public health into the medical school curriculum. Am J Prev Med. 2011;41(4 Suppl 3):S309-11.

11. Frenk J, Chen L, Bhutta ZA, Cohen J, Crisp $\mathrm{N}$, Evans T, dkk. Health professionals for a new century: transforming education to strengthen health systems in an interdependent world. Lancet. 2010;376 (9756):1923-58.

12. Carney JK, Hendrika J, Maltby HJ, Mackin KA, Maksym ME. Community-academic partnerships how can communities benefit? Am J Prev Med. 2011;41(4 Suppl 3):S206-13.

13. Maeshiro R, Koo D, Keck CW. Integration of public health into medical education. An introduction to the supplement. Am J Prev Med. 2011;41(4 Suppl 3):S145-8.

14. Jarris PE, Jarris YS, Mishori R, Sellers K. Beyond the exam room: a call for integrating public health into medical education. Acad Med. 2011;86(1):1347.

15. Fiebach NH, Rao D, Hamm ME. A curriculum in health systems and public health for internal medicine residents. Am J Prev Med. 2011;41(4 Suppl 3):S264-9.

16. Hoover CR, Wong CC, Azzam A. From primary care to public health: using problem-based learning and the ecological model to teach public health to first year medical students. J Community Health. 2012;37(3):647-52.

17. Hou Su-I. Integrating problem-based learning with community-engaged learning in teaching program development and implementation. Universal J Educational Research. 2014;2(1):1-9. 